\title{
artigo

\section{Estudos sobre a violência doméstica contra as mulheres idosas no Brasill: do simbólico ao letal}

\author{
Studies on domestic violence against elderly women in Brazil: from symbolic to lethal \\ Estudios sobre violencia doméstica contra mujeres mayores en Brasil: de simbólico a letal
}

\begin{abstract}
RESUMO
Objetivo: conhecer os índices de violência contra a mulher no Brasil, em especial, contra a mulher idosa, a qual se configura silenciosamente e tem sido objeto de discussão política e acadêmica de maneira sistemática e prolongada. Método: Trata-se de um estudo de revisão narrativa de literatura entre 1998 a 2020. Os artigos excluídos foram apresentados na metodologia deste artigo, e os incluídos nos Resultados: Nos casos analisados, a violência contra a mulher idosa prevalece, e atinge sobretudo mulheres pobres e com pouca escolaridade. Conclusões: Em 2013, os dados já apontavam que, 87\% das (mulheres idosas) já haviam sofrido violência física e sexual, e que $90 \%$ dos casos aconteceram na própria residência dos idosos, e destes $55 \%$, os autores da violência são os próprios filhos. 0 estudo apresenta o fenômeno à sociedade, visando construir estratégias e ações que permitam o seu enfrentamento.
\end{abstract}

DESCRITORES: Violência doméstica; Mulheres idosas; Simbólico ao Letal.

\section{ABSTRACT}

Objective: to know the rates of violence against women in Brazil, especially against elderly women, which is configured silently and has been the subject of political and academic discussion in a systematic and prolonged manner. Method: This is a study of narrative literature review between 1998 to 2020. The excluded articles were presented in the methodology of this article, and those included in the Results: In the analyzed cases, violence against elderly women prevails, and affects mainly women poor and poorly educated. Conclusions: In 2013 , the data already pointed out that $87 \%$ of (elderly women) had already suffered physical and sexual violence, and that $90 \%$ of the cases happened in the elderly's own residence, and of these $55 \%$, the perpetrators of violence are the own children. The study presents the phenomenon to society, aiming to build strategies and actions that allow it to be faced.

DESCRIPTORS: Domestic violence; Elderly women; Symbolic to Lethal.

\section{RESUMEN}

Objetivo: conocer las tasas de violencia contra las mujeres en Brasil, especialmente contra las mujeres mayores, que se configura de manera silenciosa y ha sido objeto de discusión política y académica de manera sistemática y prolongada. Método: se trata de un estudio de revisión narrativa de la literatura entre 1998 y 2020.Los artículos excluidos fueron presentados en la metodología de este artículo, y los incluidos en los Resultados: En los casos analizados prevalece la violencia contra las mujeres mayores, afectando principalmente a mujeres pobres. y grosero. Conclusiones: En 2013, los datos ya apuntaban que el $87 \%$ de las (ancianas) ya habían sufrido violencia física y sexual, y que el $90 \%$ de los casos ocurrieron en la propia residencia del anciano, y de estos 55\%, los autores de la violencia son los propios niños. El estudio presenta el fenómeno a la sociedad, con el objetivo de construir estrategias y acciones que permitan enfrentarlo.

DESCRIPTORES: La violencia doméstica; Mujeres de edad avanzada; Simbólico a letal.

RECEBIDO EM: 15/12/2020 APROVADO EM: 19/02/2021

\section{Jozadake Petry Fausto Vitorino}

Assistente Social pela Universidade Federal de Santa Catarina (UFSC) e Especialista em Políticas Sociais Integradas pela Universidade Estácio de Sá (Florianópolis/SC). Pós-graduanda em Saúde Pública pela Universidade EducaMais (São Paulo). Técnica de Enfermagem, especialização técnica em Enfermagem do Trabalho e Instrumentação Cirúrgica. Membro do Núcleo de Estudos da Criança, Adolescente e Família (NECAD/UFSC) e do Grupo de Estudo Virtual: Violências, Direitos e Políticas Públicas (GEV/UFSC). ORCID: 0000-0001-5656-3337 


\section{INTRODUÇÃO}

$\mathbf{N}$ o Brasil, observa-se um número significativo de violência doméstica e, particularmente nas últimas duas décadas, muitas mulheres vêm denunciando os seus agressores, os quais insistem em mantê-las em relacionamentos doentios e abusivos, fato esse que leva muitas mulheres a óbito. A autora prossegue, e classifica ainda que a violência doméstica ocorre de maneira ampliada, ao afirmar que: "as categorias sociais, alvo das agressões - físicas, sexuais, emocionais - dos machos ou de quem lhes faz as vezes". Ou seja, são agressões genéricas onde a maioria das "vítimas são mulheres, crianças e adolescentes de ambos os sexos"."

É importante salientar que, devido à SARS-CoV-2 (Covid-19), a violência doméstica contra mulheres (VDM) se intensificou ainda mais, pois as mulheres estão mais tempo e mais próximas de seus agressores bem como nos assegura Campos et al. $(2020)^{2}$ "embora seja evidente a intensificação de uma violência historicamente estruturada, expressão de um sistema de poder patriarcal que ganha novas facetas neste contexto".

Essa elevada taxa de violência no Brasil fez com que os noticiários sobre tais fatos, "migrasse de seus tradicionais redutos em editoriais e jornais especializados em crimes, alcançando destaque em todos os meios de comunicação ${ }^{3}$.

Nesse contexto, é retirado da mulher, pelo seu agressor, sobretudo das mulheres idosas, o papel do consentimento. A Lei Maria da Penha, no 11.340 de 07/08/2006, ${ }^{4}$ sancionada pelo ex-Presidente Luiz Inácio Lula da Silva, conta com 46 artigos distribuídos em sete (07) títulos. Essa Lei estabelece mecanismos importantes para não apenas coibir o agressor, mas também coibir a violência doméstica que é praticada todos os dias contra as mulheres, principalmente contra as idosas, pois elas são, sem sombra de dúvidas, as vítimas mais vulneráveis tendo em vista fatores relacionados à sua idade.

O domínio da natureza dos homens, em sua maioria, recai sobre as mulheres.
Como bem nos assegura Saffioti $(2001)^{1}$ grande parte da sociedade civil é machista e patriarcal.

Por esse ponto de vista, há algumas décadas, o homem era visto como alguém superior dentro da família; enquanto a mulher servia para cuidar dos filhos e desempenhar as atividades do lar, mantendo-se submissa ao cônjuge em todos os sentidos, já que suas preocupações diziam respeito somente aos filhos, à casa e ao aconchego de seu companheiro. Logo, não lhe cabia direitos sociais. Assim, as mulheres idosas cumpriam o papel de esposa, companheira e amiga, servindo de apoio para os dias mais difíceis do seu homem ${ }^{1}$.

É preciso lembrar, que a violência contra a pessoa idosa pode ocasionar graves consequências tanto para a saúde física e/ ou psicológica. Esses episódios ocasionam um grave problema de saúde pública "em decorrência da elevada disseminação e da severidade de suas consequências, as quais incluem traumas físicos, morais e psicoemocionais". Esses danos podem levar a vítima a incapacidade múltiplas, provocadas por diferentes graus de dependências, levando-as até a morte.

Pensamentos do mundo antigo, lamentavelmente ainda refletem no cotidiano de muitas mulheres, muito embora a Constituição Federal de $1988^{6}$, em sua esteira, aborde o tema: velhice segura e o fim da violência, essas desigualdades entre os gêneros insistem em se manter, seja pela cultura ou seus costumes já ultrapassados, pois lamentavelmente em dias atuais ainda são cultivados por muitos, seja por questões religiosas ou obediência civil, à imagem da família patriarcal, levando por exemplo, crianças a imaginar que certos comportamentos são naturais, pensamento esse que pode contribuir perfeitamente para a perpetuação da violência 7 .

Sim, o patriarcado é isso, um sistema de dominação e opressão, cujos moldes se fundam na ideologia machista da sociedade capitalista conservadora dominante. Para Costa $(2008)^{8}$ o "patriarcado é um aparelhamento sexual hierárquico da sociedade, tão imprescindível ao bem maior, o bem político". Já, para Saffiotti (2001) é
"A ordem das bicadas na sociedade humana é muito complexa, uma vez que resulta de três hierarquias/ contradições - de gênero, de etnia e de classe".

Embora existam mulheres que vivem de forma distinta, amargamente essa não é a realidade de todas, uma vez que muitas ainda sentem temor, vergonha, receio, imaginam-se incapacitadas, fracas; outras por não ter para onde ir, resolvem se calar e nada fazer para cessar a violência que sofrem dentro do seu lar, fazendo com que as agressões sofridas se prolonguem, levando-as muitas vezes a situações graves e irreparáveis, deixando nelas marcas, ou ainda, levando-as a morte?

Por fim, em relação à mulher idosa, essa violência ocorre de maneira ainda mais perversa, tendo em vista o grau de vulnerabilidade e a violência praticada, seja por meio da agressão física, pela apropriação de bens, ou até mesmo pelo abandono familiar. Em um contexto no qual as mulheres são vulneráveis, sendo que as idosas são afetadas de maneira ainda mais significativa, a problemática desse estudo é: Quais as especificidades da violência contra a mulher idosa no Brasil, e por que em muitos casos de violência, não surgem de fato os efeitos esperados pela Lei que protege essas mulheres?

Neste contexto, o objetivo geral desta pesquisa é: conhecer os índices de violência contra a mulher no Brasil, em especial, contra a mulher idosa, a qual se configura silenciosamente, e tem sido objeto de discussão política e acadêmica de maneira sistemática e prolongada.

Os objetivos específicos são: conhecer quais as especificidades da violência contra a mulher idosa; identificar as estratégias de proteção à mulher vítima de violência, e por qual razão, em muitos casos, estas não apresentam o efeito desejado pela Lei; apontar as consequências da violência na vida social e na saúde da mulher idosa.

\section{MÉTODO}

Trata-se de uma revisão narrativa da literatura. Bento (2012) $)^{9}$ argumenta que: a revisão da literatura é uma parte vital do 
processo de investigação prévia em artigos, "é então, uma análise bibliográfica pormenorizada, referente aos trabalhos já publicados sobre o tema". A busca do material foi realizada de agosto a dezembro de 2020 e a coleta de dados por meio da consulta ao Google Scholar e na base de dados do SciELO aplicando as palavras-chave "violência" AND "mulher idosa" e "violência" AND "idoso" e "idosas" AND "violência”. No que tange à escolha da seleção e da leitura do material ocorreu por meio de artigos que atendessem aos objetivos propostos em nosso estudo, não havendo a necessidade de incluir outras bibliografias, pois não atendiam a necessidade de nossa proposta. Os artigos escolhidos sobre a violência contra as mulheres idosas, foram publicados em idioma português entre os anos de 1998 a 2020.

Critérios de exclusão de artigos: Artigos irrelevantes, foram excluídos 3. Artigos repetidos, foram excluídos 7. Artigos incompletos e que fugiam do nosso tema, foram excluídos 10. Os Artigos analisados em outras referências, foram excluídos 5 . Em relação aos Artigos incluídos, estes serão apresentados nos resultados mediante a contraposição de autores dos Artigos analisados em nosso estudo, sobre a violência doméstica contra as mulheres idosas no Brasil: do simbólico ao letal.

Por fim, é importante dizer que após coletar os dados, a etapa seguinte teve por objetivo elaborar a análise e realizar a interpretação dos dados obtidos, que, segundo Triviños $(2008)^{10}$, apoia-se nos resultados alcançados no estudo, na fundamentação teórica e na experiência pessoal própria do investigador.

\section{Violência contra as mulheres idosas: uma das expressões da questão social}

A violência na velhice é um fenômeno complexo e difícil de ser conceituado. Ela pode ser realizada ou sofrida por indivíduos de qualquer classe social, grupo ou nação. Esse fenômeno não é atual ou exclusivo da contemporaneidade. Suas raízes encontram-se nas estruturas sociais, político-econômicas e, por que não dizer, na própria consciência individual dos sujeitos.
A diversidade da violência pode ser compreendida como o uso propositado da força física, geralmente engendrada e alimentada por uma relação assimétrica de poder entre o agressor e a vítima real ou em potencial, "contra si próprio, contra outras pessoas ou contra um grupo ou uma comunidade, que resulte ou tenha possibilidade de resultar em lesão, morte, dano psicológico, deficiência de desenvolvimento ou privação ${ }^{11}$.

A violência na velhice também é uma das expressões da questão social. Iamamoto $(2001)^{12}$, afirma que a violência na sociedade atual não deixa de ser um "conjunto das expressões das desigualdades sociais engendradas na sociedade capitalista madura, impensáveis sem a intermediação do Estado".

Necessário se faz dizer que, a violência cometida contra a população idosa tem implicações para a saúde física e mental e tem se tornado um problema sério de saúde pública, em virtude do aumento das ocorrências nos últimos tempos no Brasil e principalmente da severidade de suas consequências, "as quais incluem traumas físicos, morais e psicoemocionais. Esses danos podem ocasionar incapacidade, dependência e até mesmo morte".

Infelizmente esse fato não é algo incomum, muito embora tenha acontecido modificações no meio social, em relação às mudanças conquistadas pelas mulheres, a sociedade ainda respira certos conceitos antigos; ainda se vê em um meio patriarcal e muito machista - onde o pai é o alicerce, a estrutura, e todos os outros membros da família se submetem a ele, inclusive sua esposa. Essa visão de submissão gera no homem sentimentos de autoritarismo, posse, e abre precedentes para que ele a mantenha submissa a suas vontades, discrimine-a, despreze-a e, por derradeiro, mate-a.

Ao se remeter ao sistema de alerta, Duque et al. $(2012)^{13}$ concluem que à violência contra a pessoa idosa no ambiente doméstico é o primeiro passo para o estudo do fenômeno, uma vez que tem se tornado um grave problema de Saúde Pública. Diante disso, é fundamental que ocorra a ampliação de investigações na (matriz) desta área.

\section{0 ambiente familiar, por vezes, é um espaço seguro para a pessoa idosa?}

A família tem sido tradicionalmente vista de uma perspectiva unidimensional, como um refúgio, tendo sido descrita como uma estrutura social básica mais ampla, da qual recebemos quase tudo: desde o auxílio material ao apoio espiritual. Apoio este que inclui a educação, os valores, as proibições morais, bem como os estímulos sociais. Na verdade, a família é o espaço onde se desenvolve a solidariedade entre as gerações. No entanto, as famílias nem sempre são um refúgio seguro e idílico; às vezes são locais perigosos para o indivíduo e, espaços onde as pessoas idosas são vítimas de diversos tipos de maus-tratos.

Nóbrega et al. (2019) ${ }^{14}$ buscaram verificar quais são as representações sociais de mulheres, vítimas de violência doméstica, acerca da natureza do comportamento dos seus agressores mediante uma pesquisa qualitativa realizada com 20 mulheres protegidas pelo Centro de Referência de Natal/RN. Discute-se que a violência contra a mulher está diretamente associada ao modo como a sociedade concebe os papéis de gêneros, colocando a mulher em uma condição de subalternidade. A maioria dos casos de violência contra a mulher relatados ocorre nos espaços intrafamiliares, ou seja, dentro de casa. Razão pela qual, a violência acometida contra a pessoa idosa é muito complexa, uma vez que se a vítima não denunciar o autor da agressão, as autoridades nada podem fazer.

Como bem no assegura Silva e Dias (2016) "15 "90\% dos casos de violência acontecem na própria residência dos idosos. $\mathrm{E}$, o que é pior, em $55 \%$ dos casos, os agressores são os próprios filhos". As autoras concluem: "Muitos casos ocorrem depois que os agressores se apropriam indevidamente das aposentadorias das vítimas ${ }^{15 "}$.

As mulheres compartilham a residência com o agressor, que a entende como sua, esse sentimento de posse é um dos fatores que determina as diferentes manipulações tóxicas e abusivas.

A violência intrafamiliar pela qual inúmeras mulheres idosas são acometidas todos os dias, acontece mesmo que os seus 
agressores não residam com elas. Com relação a isso, Nobrega et al. (2019) ${ }^{14}$ salienta que: "Observa-se que a violência traduz a construção social de gênero que determina as relações hierarquizadas entre homens e mulheres, mediante a delimitação de seus papéis sociais enraizados culturalmente". Vivem em um contexto no qual a mulher é considerada a principal responsável pelo cuidado e pelo comportamento masculino, em uma relação maternal que não se rompe, nem após a vida adulta, logo, acabam se culpabilizando pela violência sofrida. Muitas delas decidem manter o vínculo com o agressor, porque se sentem responsável pela violência e com medo de negar aos filhos a convivência com o pai, decidindo, portanto, permanecer nesse relacionamento doentio. A partir de um modelo de família tradicional legitimado socialmente, a mulher agredida opta pela manutenção do status quo, ainda que para isso precise se submeter a diversas situações de violência todos os dias.

Em contrapartida, as representações sociais em relação a mulheres solteiras, mães solos e mulheres divorciadas contribuem com essa conduta. Muitas delas são capazes de reconhecer a violência como um crime, e decidem dar um basta quando passam por algum episódio de violência com os seus ex-companheiros dentro de casa. Eis aí uma postura adequada, dizer não à violência, até porque aquilo que não queremos para nós, tampouco havemos de querer para os nossos filhos.

\section{A importância da capacitação dos profissionais da saúde em casos de violência doméstica contra as mu- Iheres idosas (VDM)}

As mulheres, vítimas de diferentes tipos de violência doméstica, buscam os serviços de saúde para relatar o que estão passando e sentindo, e após constatados os maus-tratos, uma Equipe de Profissionais da Saúde é acionada para fazer uso de diferentes intervenções, as quais poderão ser de ordem multiprofissional, interdisciplinar e interinstitucional. Multiprofissional porque exige a atuação de diversas áreas do conhecimento como: Medicina, Enferma- gem, Serviço Social, Psicologia, Direito; interdisciplinar por envolver toda a equipe de assistência na atenção à saúde dos pacientes que vêm em busca de orientação e/ou um atendimento e, interinstitucional por envolver a extensão de outras instituições que atuam de forma complementar, colaborativa e intersetorial. Essas intervenções precisam ser realizadas por profissionais qualificados, todavia, não somente profissionais capazes de orientá-las para a situação de violência vivida, mas também, que possam de fato, fortalecê-las para o real enfrentamento, e assim, estabelecer a mudança de pensamento, a fim de concretizar a denúncia contra os seus algozes. Entretanto, mesmo os profissionais experientes possuem representaçôes sociais acerca da vítima e do agressor que podem influenciar a sua abordagem à vítima.

Ao investigar os níveis de conhecimento de profissionais de Equipe da Saúde da Família (PSF) sobre a violência de gênero e possíveis protocolos de tratamento, Martins et al. $(2018)^{16}$ argumenta que, os profissionais com maior tempo de capacitação, são aqueles que apresentam melhores conhecimentos sobre os contextos e a caracterização das vítimas de violência doméstica, assim como também, apresentam melhores condições para compreender os protocolos de cuidados.

Guimarães et al. (2018) um estudo transversal cuja coleta de dados utilizou as informações do Sistema de Informação para a Vigilância de Violência e Acidentes do ano de 2013, buscaram caracterizar a população de mulheres idosas, vítimas de violência física e sexual no Brasil. Os autores identificaram que $87 \%$ das vítimas eram agredidas por membros da família, principalmente do sexo masculino. Quando o agressor não era familiar, era conhecido da vítima. A maioria das vítimas, cerca de $95 \%$, sofreram agressão física, e $5 \%$ foram vítimas de violência sexual.

Nesse sentido, é necessário que as vítimas conheçam os seus limites na relação, e identifiquem quando eles estão sendo ultrapassados, para assim, criar coragem e romper essa relação abusiva e tóxica, garantindo com isso, a preservação da saúde mental, física e emocional, e por vezes, da própria vida.

Atualmente, devido às tecnologias de informação, a saída da mulher para a vida pública está mais voltada para episódios repetitivos de tensão, de repressão e, consequentemente, de violência, acima de tudo no âmbito familiar, caracterizada como silenciosa. É preciso dar um basta no silêncio passivo e agressivo, oferecendo denúncia contra quem está causando danos ao outro.

Entretanto, é importante que as vítimas de violências saibam que a mulher, até mesmo as mais idosas, é sempre superior ao seu agressor, pois está provida de qualidades, e uma delas é a força da sua voz. A ingenuidade em relação à sua dor, e o susto da agressão que sofreu, levou-a, por vezes, a não revidar, fato esse que ocorre principalmente devido à fragilidade ocasionada pela idade. Mas quando a vítima decide tornar pública a agressão, declarar a sua dor e superar o trauma, auxilia outras mulheres, que foram e são agredidas todos os dias, a expor a sua privacidade e a manter-se vivas.

Diante dos fatos, Guimarães et al. $(2018)^{5}$ evidenciam que existe sim a necessidade de capacitação específica para os profissionais da unidade básica de saúde, pois os atendimentos de violência contra a pessoa idosa, inclusive por parte de seus familiares, são frequentes, por isso a importância dos profissionais que atuam nos serviços de saúde, principalmente o próprio médico. É preciso que todos estejam aptos a prestar um atendimento com competência e habilidade, com vistas a uma melhor identificação, prevenção, convencimento e acompanhamento e ao enfrentamento de casos de violência. E, posteriormente, que esses atendimentos sirvam de referencial para embasar as pesquisas sobre essa temática, com o intuito de guiar o reconhecimento de novas ações preventivas e a formulação de políticas públicas e sociais mais efetivas para o enfrentamento da violência contra a pessoa idosa.

Outrossim, os autores apontam que existem muitos atendimentos e subnotificações na atenção básica de saúde, mas tendo em vista à escassez de monitora- 
mento e de um registro contínuo adequado e padronizado sobre violência, perde-se o acompanhamento. Esta situação se repete com mais frequência, quando as vítimas são: "crianças, mulheres, homossexuais, idosos, doentes, pobres e moradores de rua, o que leva a interpretar que existem pessoas não reconhecidas como cidadãos e que carecem de direitos".

A maioria dos casos relatados pelas Equipe da Saúde da Família (ESF) são encaminhados para outros serviços profissionais que atuam na Assistência Social como: CRAS, CREAS, PAEFIs e CREMVS.

Entendemos que esses serviços de escuta especializada, prestados à população, viabilizam processos de socialização para melhor assimilar as violências cometidas contra as mulheres todos os dias, ampliando o trabalho de escuta e acolhida, a fim de alcançar não só as vítimas, mas também os autores da violência, pois desse modo, obteremos a mudança de pensamento e de atitudes da sociedade adoecida. A Lei 13.984, de 3 de abril de $2020^{17}$, trouxe importantes medidas protetivas determinadas pelo Juiz, a fim de que o autor da violência seja inserido ao Programa de Apoio Psicossocial (PAP) com o propósito de ser reeducado mediante atendimento individual ou grupal, para que, de fato, possa ocorrer a mudança de pensamento e de comportamento.

Por fim dizer, que toda e qualquer violência contra as mulheres idosas pode e deve ser evitada, mas para isso, é imprescindivel que os profissionais da unidade básica de saúde recebam constantemente a capacitação específica para melhor atender os casos de violências contra a mulher todos os dias. E preciso também, que sejam elaboradas novas políticas públicas integradas, inclusivas e qualitativas com avaliações periódicas in loco.

\section{DISCUSSÃO}

$\mathrm{Na}$ sociedade capitalista, machista e desigual, a mulher é socializada e educada para cuidar da família, dos afazeres domésticos, amar o seu marido, e agradá-lo. Esse pensamento ainda está impregnado na cabeça de muitas pessoas, principalmente as mais conservadoras ${ }^{18}$.

A necessidade de cuidado do idoso por um parente faz emergir conflitos que resultam na violência por algum membro da família ou por um cuidador remunerado. Contudo, por falta de estatísticas concretas é difícil quantificar com precisão essas brutalidades.

Vale destacar, que existe dificuldade na identificação da violência contra a pessoa idosa, pois em geral as vítimas protegem os seus agressores, os quais costumam ser entes queridos. Pelo exposto, constata-se que não é nada fácil identificar a violência contra a pessoa idosa, porque na maioria das vezes o fenômeno permanece velado pela própria vítima, durante anos, ou por toda a vida.

Ainda com relação ao tema, a violência pode ser cometida pelos próprios familiares, pelos amigos da vítima e da família, e por estranhos. Às vezes, os vizinhos ficam sabendo que naquela família existe algo de errado, mas ninguém quer se envolver em nenhuma zona de conflitos e, por isso, preferem se manter calados em relação à denúncia, mas de certo modo, eles buscam alguém próximo da família para relatar o que está acontecendo naquele domicílio. Como bem nos assegura Mascarenhas et al. $(2012)^{19}$ as violências "podem vir das próprias pessoas idosas, das famílias, dos cuidadores, dos próprios profissionais, e até mesmo da sociedade que não enxerga a violência contra a pessoa idosa”.

Todavia, identificar onde está ocorrendo a violência e sobretudo com quem está acontecendo é uma das responsabilidades que cabe ao profissional da saúde da família. É certo que este agente pode enfrentar algumas barreiras e obstáculos para a identificação da violência doméstica, por isso, é importantíssimo que durante o atendimento, os profissionais realizem uma escuta qualificada, para assim, romper todas as barreiras do silêncio.

Como já foi relatado ao longo do texto, entre as dificuldades encontradas para se revelar a violência contra a pessoa idosa está a negação por parte da vítima, sobre- tudo em casos de violência psicológica cometida pelos próprios filhos. A vítima costuma não admitir que está sofrendo maus-tratos para proteger o agressor, e ainda pela naturalização desses episódios. Ademais, após ser feita a denúncia, há também o medo de que o agressor se torne ainda mais violento. $\mathrm{O}$ artigo $2^{\circ}$, da Lei Maria da Penha, certifica a proteção a todas as mulheres, independente de "classe, raça, etnia, orientação sexual, renda, cultura, nível educacional, idade e religião ${ }^{4 "}$

Quanto à velhice, é inegável que está associada à vulnerabilidade e fragilidade. A sociedade, por vezes, coloca os idosos em posição subordinada, ainda que seja verdade que as novas gerações que entram nesta fase da vida apresentam um peso social e político crescente. Trata-se de uma subordinação que tem manifestações materiais, como a pobreza, mas também psicológicas, como a solidão. ${ }^{20}$

Por outro lado, a situação do idoso está associada à mudança social e familiar. Apesar da persistência de estruturas familiares tradicionais, a ideia da família como um espaço de acolhimento e de cuidados as mulheres idosas, vítimas de violência doméstica é cada vez mais questionada. Neste sentido, considera-se que o Estado tem um papel a desempenhar no apoio aos cuidadores, bem como na transposição de obstáculos e dificuldades associadas às atividades de assistência, quando produzem situações de vulnerabilidade e de desigualdade.

A sociedade costuma definir os maus-tratos aos idosos de maneira mais branda, como tratamento inadequado ou falta de atenção aos idosos. No entanto, a negligência e o abuso econômico ou material são tipos claramente identificados; e ainda há relatos de abuso sexual.

Em relação à visão dominante que associa os maus-tratos ao transbordamento e ao estresse dos cuidadores familiares, a negligência ocupa um lugar central. Nessa linha, cuidar de idosos dependentes (principalmente se eles sofrem de demência), gera uma situação de opressão e estresse que pode levar ao abandono. Contudo, essa negligência não é vista claramente como uma forma de abuso ou violência 
contra os idosos. É como se a negligência fosse mais aceitável.

Dessa forma, no discurso sobre a violência de gênero na velhice existem duas vertentes: a) a violência de gênero contra as mulheres idosas desafia a visão ortodoxa do fenômeno, segundo a qual apenas as mulheres jovens ou de meia-idade sofrem abuso por parte de seus parceiros; b) os maus-tratos às mulheres idosas por seus companheiros são vistos, de certa forma, como uma realidade diferente dos maus-tratos familiares aos idosos.

Como bem nos assegura Santos et al. $(2013)^{21}$ quando afirmam que "A complexidade das relações interpessoais, inclusive as intergeracionais, obriga ao reconhecimento do conflito e da ambivalência como parte integrante daquelas, e à diferenciação entre tensão, conflito e violência na esfera familiar".

Logo, enquanto o conhecimento científico caminha na construção de pesquisas que apresentam tal problemática para a sociedade, muitas mulheres idosas são vitimadas de maneira silenciosa.

\section{RESULTADOS}

Em diversas famílias na sociedade contemporânea, as relações acontecem de forma tensa e tóxica. Por vezes, ainda somadas a ideia ultrapassada de que a velhice é um período da vida que representa desprezo e inutilidade. Esses sentimentos: "geram o ambiente propício para que se estabeleçam interações conflituosas e violentas, seja entre os casais idosos, entre os filhos e idosos ou mesmo entre cuidadores e idosos ${ }^{22}$.

Santos et al. (2013) ${ }^{21}$ também buscaram identificar a prevalência dos maus-tratos contra indivíduos idosos. Em um estudo realizado com a população europeia, os autores perceberam que as pesquisas a esse respeito são escassas, sendo necessária, pois, a construção de um amplo arcabouço teórico capaz de explicar esse fenômeno e traçar possibilidades de enfrentamento, e destacam que as relações intrafamiliares, quando por sua natureza são complexas, são sentimentos que por vezes, perpassam entre a vítima
- a mulher idosa - e o seu agressor, uma relação de amor e ódio.

Como bem no assegura Silva e Dias (2016)22 "90\% dos casos de violência acontecem na própria residência dos idosos. E, o que é pior, em $55 \%$ dos casos, os agressores são os próprios filhos". As autoras concluem: "Muitos casos ocorrem depois que os agressores se apropriam indevidamente das aposentadorias das vítimas ${ }^{22 "}$.

Mascarenhas et al. (2012) ${ }^{19}$ descreveram notificações de violência contra idosos desenvolvidas pelo Sistema de Informação de Agravos de Notificação - versão Net (Sinan Net) em 2010. Os resultados indicaram que $52,3 \%$ dos idosos vítima de violência no Brasil são do sexo feminino. A maioria das idosas vítima de violência tiveram seus filhos como agressores, foi do tipo psicológica e realizada de maneira contínua. As idosas também foram as maiores vítimas de abandono parental e negligência. Em relação à prevalência, os autores estimam que a violência contra os idosos atinja entre 7 e 14\% dessa população. Para os autores, a pesquisa acerca do predomínio da violência contra a mulher no Brasil é incipiente, sendo necessários maiores estudos que identifiquem de maneira mais assertiva esses dados, com a finalidade de subsidiar políticas de enfrentamento a esse tipo de episódio.

Guimarães et al. (2018) , por meio de um estudo transversal cuja coleta de dados utilizou as informações do Sistema de Informação para a Vigilância de Violência e Acidentes do ano de 2013, buscaram caracterizar a população de mulheres idosas, vítimas de violência física e sexual no Brasil. Os autores identificaram que $87 \%$ das vítimas eram agredidas por membros da família, principalmente do sexo masculino. Quando o agressor não era familiar, era conhecido da vítima. A maioria das vítimas, cerca de $95 \%$, sofreram agressão física, e $5 \%$ foram vítimas de violência sexual.

Em casos de violência com relação à assistência, os autores verificaram que os dados apontam que somente $13 \%$ dos casos foram encaminhados para o Conselho Tutelar do Idoso, enquanto as demais vítimas ao serem liberadas do hospital, precisavam retornar, sem qualquer acompanhamento, ao lugar que sofreram violência. Razão pela qual, muitas vítimas deixam de oferecer a denúncia protegendo assim, os seus agressores, sugerindo desta maneira, que ainda falta de fato que as políticas públicas e sociais surtam seus reais efeitos, oferecendo as vítimas, acolhimento, proteção e acompanhamento na matriz contínuo5.

A velhice e a vulnerabilidade intensificam o risco de violência que atinge os mais pobres, pois segundo o Instituto Nacional de Estatísticas Econômicas (INSEE), 70\% dos pobres com mais de 75 anos são mulheres que vivem nas regióes mais isoladas das cidades, em condições insalubres, o que as torna mais frágeis física ou psicologicamente. Lembrando que essas mulheres apresentam um acúmulo gigantesco de vulnerabilidades. A análise da vulnerabilidade programática das mulheres à violência permite compreender sua maior ou menor suscetibilidade, enfocando políticas, ações, serviços, e as estratégias disponibilizadas e institucionalizadas que deveriam apresentar respostas efetivas para mitigar essa violência ${ }^{22}$.

Entretanto, segundo Guimarães et al., $(2018)^{5}$ autor de estudo transversal, realizado com base em dados e informaçôes do Sistema de Informação para a Vigilância de Violência e Acidentes, relata que os dados, em 2013, já apontavam que no Brasil $87 \%$ das vítimas (mulheres) idosas já sofreram violência física e sexual, e que geralmente elas são agredidas pelos próprios membros da família, principalmente, os do sexo masculino. Em casos em que o agressor não era familiar, era conhecido da vítima. A maioria das vítimas, cerca de $95 \%$ sofreram agressão física e $5 \%$ das vítimas sofreram violência sexual.

Meirelles Júnior et al. $(2019)^{20}$ buscaram descrever o perfil da violência praticada contra a pessoa idosa no Brasil, por meio de um estudo retrospectivo no qual foram analisados os dados do Sistema de Informação de Agravos de Notificação (SINAN), de 2012 a 2017, para o estado de Minas Gerais. Os resultados indicam que $54,5 \%$ dos idosos vítima de violência doméstica no Brasil são do sexo femini- 


\section{artigo}

Estudos sobre a violência doméstica contra as mulheres idosas no Brasil: do simbólico ao letal

no, brancas, e com Ensino Fundamental incompleto. Os autores também identificaram o filho como principal responsável pela agressão. A baixa escolaridade foi identificada como um fator de risco para a violência contra mulheres idosas. Mulheres idosas que frequentaram a escola por curtos períodos tendem a ser mais dependentes financeiramente de familiares, algo que pode gerar conflitos. Muitas vezes mais pobres, mais isoladas, mais fragilizadas física e ou psicologicamente, as mulheres idosas apresentam uma pluralidade de vulnerabilidades.

Nas campanhas de prevenção a violência, as mulheres vítimas de abuso são mães, geralmente jovens, uma vez que os estudos sobre violência doméstica no Brasil enfocam mulheres jovens e as pessoas idosas, deixando comprovado que todas as faixas etárias são afetadas ${ }^{23}$.

De acordo com Campos, et al. $(2020)^{2}$ "no contexto da Pandemia em curso, fatores que aumentam a vulnerabilidade social à VDM, como falta de renda, a fome, o desemprego, somam-se à precarização de programas" que visam atender as necessidades imediatas das famílias menos favorecidas, que garantem creches, escolas e nelas a alimentação que muitas famílias pobres necessitam para seus filhos, bem como para os seus idosos. Essas ações são resultado de movimentos sociais que, há muitos anos, buscam diminuir a violência que se encontra ancorada na desigualdade social e no gênero. Associado a isso, está o acúmulo de afazeres aos cuidados da mãe, mulher, por vezes idosa, dona dos cuidados da sua casa, dos filhos, dos seus maridos, e dos enfermos, trazendo ainda a insegurança e o medo de adoecer pela Covid-19.
É importante salientar, que mesmo antes do surgimento da SARS-CoV-2 (Covid-19) já existia a escassez de recursos materiais e humanos para os serviços relacionados à saúde. Conforme Campos et al. $(2020)^{2} \mathrm{O}$ "corte no repasse de verbas, a precariedade nas Delegacias da Mulher e a falta de interesse na capacitação/treinamento de profissionais, um sucateamento visível nos três níveis de governo (municipal, estadual e federal)".

Ao se remeter ao sistema de alerta, Duque et al. $(2012)^{13}$ concluem que à violência contra a pessoa idosa no ambiente doméstico é o primeiro passo para o estudo do fenômeno, uma vez que tem se tornado um grave problema de Saúde Pública. Diante disso, é fundamental que ocorra a ampliação de investigações na (matriz) desta área.

Guimarães et al. (2018)5 chama a atenção para a necessidade de capacitação específica para os profissionais da Unidade Básica de Saúde para melhor atender as mulheres vítimas de violência doméstica.

Já Martins et al. $(2018)^{16}$ argumenta que, os profissionais com maior tempo de capacitação, são aqueles que apresentam melhores conhecimentos sobre os contextos e a caracterização das vítimas de violência doméstica, assim como também, apresentam melhores condições para compreender os protocolos de cuidados.

Por fim dizer que, segundo Campos, et al. $(2020)^{2}$ é urgente formular e implementar novas ações que possam atender o contexto de violências sofrida pelas mulheres, $\mathrm{e}$ que de fato atenda às suas reais necessidades no que tange a ampliação ou criação de novas casas de abrigos; acolhimento em casos de agravos no uso de drogas, de álcool ou na ausência de saúde mental. Além disso, é preciso melhorar o apoio mediante ampliação da oferta de cestas básicas e de outros insumos necessários à sobrevivência das vítimas. Nos casos de atendimento profissional, é importante que sejam criados mecanismos éticos de sigilo, oferecendo à vítima maior conforto e segurança; implementar mudanças, principalmente no que diz respeito ao discurso de governantes frente à promoção de ações e medidas para obter sucesso no enfrentamento da violência contra mulheres, principalmente aquelas com idade mais avançada.

\section{CONCLUSÃO}

O abuso contra as mulheres idosas é um tema que cresce a cada dia no campo mais genérico da violência intrafamiliar. Trata-se de um fenômeno que exige maior visibilidade social por parte das autoridades, da sociedade, como também merecem atenção especial por parte dos profissionais que atuam em rede na área da saúde, até porque essa realidade ainda não é revelada, e, portanto, para muitos, não é vista como um problema social urgente. Conclui-se que os maus-tratos aos idosos, na sua dimensão familiar e na sua dimensão institucional constitui-se em um fenômeno multifacetado a experiências particulares extremamente complexas ligadas ao envelhecimento da população, à posição social dos idosos, ao papel da família, à saúde pública, às políticas sociais, ao desenvolvimento do estado de bem-estar, à bioética e ao direito. Assim sendo, esses diferentes campos exigem transformações profundas na atual estrutura de sociedade para que a pessoa idosa possa, de fato, ser protagonista de sua história.

\section{REFERÊNCIAS}

1. Saffioti HI. Contribuições feministas para o estudo da violência de gênero. Cad. Pagu [Internet]. 29 de março de 2016 [citado 19 de fevereiro de 2021];(16):115-36. Disponível em: https:// periodicos.sbu.unicamp.br/ojs/index.php/cadpagu/article/ view/8644541

2. Campos BB, Tchalekian B, Paiva VSF. Violência contra a mul- her: vulnerabilidade programática em tempos de sars-cov-2/ covid-19 em São Paulo [Internet]. Psicologia e Sociedade. 2020 ; 32 1-20.Available from: http://dx.doi.org/10.1590/18070310/2020v32240336

3. Rondelli E. Imagens da violência: práticas discursivas. Tempo Soc. [Internet]. 1 de dezembro de 1998 [citado 19 de fevereiro 


\section{REFERÊNCIAS}

de 2021];10(2):145-57. Disponivel em: https://www.revistas. usp.br/ts/article/view/86785.

4.BRASIL. Lei $n^{\circ} 11.340$, de 7 de agosto de 2006. Lei Maria da Penha. Cria mecanismos para coibir a violência doméstica e familiar contra a mulher, nos termos do $\S 8^{\circ}$ do art. 226 da Constituição Federal, da Convenção sobre a Eliminação de Todas as Formas de Discriminação contra as Mulheres e da Convenção Interamericana para Prevenir, Punir e Erradicar a Violência contra a Mulher; dispõe sobre a criação dos Juizados de Violência Doméstica e Familiar contra a Mulher; altera o Código de Processo Penal, o Código Penal e a Lei de Execução Penal; e dá outras providências. Disponivel em: http://www.planalto.gov.br/ ccivil_03/_ato2004-2006/2006/lei/l11340.htm. Acesso em: 28 nov. 2020.

5. Guimarães Ana Paula dos Santos, Górios Carlos, Rodrigues Cintia Leci, Armond Jane de Eston. Notification of intrafamily violence against elderly women in the city of São Paulo. Rev. bras. geriatr. gerontol. [Internet]. 2018 Feb [cited 2021 Feb 19] ; 21( 1 ): 88-94. Available from: http://www.scielo.br/scielo. php?script=sci_arttext\&pid=S1809-98232018000100088\&Ing=en. https://doi.org/10.1590/1981-22562018021.160213.

6.BRASIL. Constituição da República Federativa do Brasil de 1988, de 5 de outubro de 1988. Brasília, DF: Presidência da República, 1988.

7. Caldas, L. S., Fortaleza, K. R., Silva, P. V. C., Brito, L. O., Bethâ, M., \& Brandã, C. (2008). Violência contra a mulher idosa: vozes silenciadas. Geriatrics, Gerontology and Aging, 2(4), 167-175.

8.Costa, Ana Alice. Gênero, poder e empoderamento das mulheres. Bahia, 2008. Disponivel em: http://www.neim.ufba.br/ site/arquivos/file/textosapoio1.PDF. Acesso em: nov. de 2020.

9.Bento, A. (2012, Maio). Como fazer uma revisão da literatura: Considerações teóricas e práticas. Revista JA (Associação Académica da Universidade da Madeira), nº 65, ano VII (pp. 4244).

10.Trivinos, A. N. S. Introdução à pesquisa em ciências sociais: a pesquisa qualitativa em educação. São Paulo: Atlas, 2008.

11.Pinheiro, P. S.; Almeida, G. A. Violência Urbana. São Paulo: Publifolha, 2003.

12.lamamoto, Marilda Villela. A questão social no capitalismo. In. Revista da Associação Brasileira de Ensino e Pesquisa em Serviço Social - ABEPSS. Brasília. ABEPSS, 2001.

13. Duque Andrezza Marques, Leal Márcia Carrera Campos, Marques Ana Paula de Oliveira, Eskinazi Fernanda Maria Vieira, Duque Amanda Marques. Violência contra idosos no ambiente doméstico: prevalência e fatores associados (Recife/PE). Ciênc. saúde coletiva [Internet]. 2012 Aug [cited 2021 Feb 19] ; 17( 8 ): 2199-2208. Available from: http://www.scielo.br/scielo.php?script=sci_arttext\&pid=S1413-81232012000800030\&lng=en. http://dx.doi. org/10.1590/S1413-81232012000800030.

14. Nóbrega Vannucia Karla de Medeiros, Pessoa Júnior João Mário, Nascimento Ellany Gurgel Cosme do, Miranda Francisco
Arnoldo Nunes de. Renúncia, violência e denúncia: representações sociais do homem agressor sob a ótica da mulher agredida. Ciênc. saúde coletiva [Internet]. 2019 July [cited 2021 Feb 19] ; 24 ( 7 ): 2659-2666. Available from: http://www.scielo.br/scielo. php?script=sci_arttext\&pid=S1413-81232019000702659\&Ing=en. Epub July 22, 2019. http://dx.doi.org/10.1590/141381232018247.16342017.

15. Silva CFS, Dias CMSB. Violência contra idosos: perfil sociodemográfico dos familiares agressores, tipos de violência impetrada e motivações para sua ocorrência. Rev Eletron Gestão Saúde. 2015;7(2):563-81. DOI: 10.18673/gs.v7i2.22040

16.Martins LCA, Silva EB, Dilélio AS, Costa MC, Colomé ICS, Arboit J. Violência de gênero: conhecimento e conduta dos profissionais da estratégia saúde da família. Rev. Gaúcha Enferm. 2018;39:e2017-0030.

17. BRASIL. Lei 13. 984, de 3 de abril de 2020. Altera o art. 22 da Lei $n^{\circ}$ 11.340, de 7 de agosto de 2006 (Lei Maria da Penha), para estabelecer como medidas protetivas de urgência frequência do agressor a centro de educação e de reabilitação e acompanhamento psicossocial. Brasília - DF. Disponivel em: http://www. planalto.gov.br/ccivil_03/_Ato2019-2022/2020/Lei/L13984. htm. Acesso em: 02 dez. 2020.

18.Damaceno, Daniela Garcia et al. Mulheres idosas vítimas de violência: estudo de casos múltiplos. CIAIQ2018, [s. I], v. 2, p. 779-788, 2018. Disponível em: https://proceedings.ciaiq.org/ index.php/ciaiq2018/article/view/1848/1798. Acesso em: 23 dez. 2020.

19. Mascarenhas Márcio Dênis Medeiros, Andrade Silvânia Suely Caribé de Araújo, Neves Alice Cristina Medeiros das, Pedrosa Ana Amélia Galas, Silva Marta Maria Alves da, Malta Deborah de Carvalho. Violência contra a pessoa idosa: análise das notificações realizadas no setor saúde - Brasil, 2010. Ciênc. saúde coletiva [Internet]. 2012 Sep [cited 2021 Feb 19]; 17(9): 2331-2341. Available from: http://www.scielo.br/scielo.php?script=sci_arttext\&pid=S1413-81232012000900014\&Ing=en. https://doi. org/10.1590/S1413-81232012000900014.

20. Meirelles RC Jr, Castro JO, Faria LR, Silva CLA, Alves WA. Notificações de óbitos por causas externas e violência contra idosos: uma realidade velada. Rev Bras Promoç Saúde. 2019;32:1-12.

21. Ana João Santos, Rita Nicolau, Ana Alexandre Fernandes e Ana Paula Gil, «Prevalência da violência contra as pessoas idosas: uma revisão crítica da literatura », Sociologia, Problemas e Práticas [Online], 72 | 2013, posto online no dia 22 abril 2013, consultado o 19 fevereiro 2021. URL: http://journals.openedition.org/spp/1192

22. Silva CFS, Dias CMSB. Violência contra idosos na família: motivações, sentimentos e necessidades do agressor. Psicol Ciênc Prof. 2016 jul-set;36(3):637-52.

23.Freitas, C.O.M de. Riva, Léia Comar. Violência doméstica como violação dos direitos da mulher idosa. An. Sciencult, Panaraíba, v. 7, n. 1, p. 56-72, 2017. Disponivel em: https://anaisonline.uems. br/index.php/sciencult/article/view/4640/4657. Acesso em: 23 dez. 2020. 